\title{
The Effect of Teacher Support on Migrant Children's Academic Achievement: A Moderated Mediation
}

\author{
Xiuqin TENG \\ Department of Teacher and Education, Qilu Normal \\ University, Jinan, Shandong, China \\ e-mail: winterqinxt@126.com
}

\author{
Guirong LIU* \\ Department of Teacher and Education, Qilu Normal \\ University, Jinan, Shandong, China \\ e-mail: ganenxiaowai@163.com \\ *Corresponding author
}

\begin{abstract}
This study attempted to examine the relationship between teacher support and migrant children's academic achievement as well as the mediating role of self-esteem and the moderating role of psychological control. Six hundred and six migrant children participated in the study and the teacher support they perceived and their self-esteem were measured. Their academic achievements were acquired from the school dean's office. Results showed that:1) Positive self-esteem mediated the positive relation between teacher support and migrant children's academic achievement; 2) Psychological control moderated the relation between teacher support and positive self-esteem, such that the relation was weaker when the level of psychological control is high rather than low; 3) Psychological control moderated the mediating effect of positive self-esteem on teacher support-migrant children's academic achievement relationship, such that the mediating effect was weaker when the level of psychological control was high.
\end{abstract}

Keywords-Teacher support; Academic achievement; Positive self-esteem; Psychological control

\section{INTRODUCTION}

In search of better living condition, China's large-scale and persistent rural-to-urban migration has taken place in the past three decades. By the end of 2014, Migrant population by National Population is 253 million (Population Census Office under the State Council, 2014), of which 35.81 million were children between 6-14 years old or 7-15 years old and the number is still increasing (Population Census Office under the State Council, 2012; ACWF Research Group, 2013). Academic achievement is not only the important criteria of measuring students level changes, but also reflects teachers' management level. With the development of Active Psychology, studying the effect of teacher behaviors on students' achievement changes from teachers' passive behaviors (Assor, KaPlan, Kanat-Maymon, \& Roth,2005) to active ones, such as teacher-student interaction (Allen, et al., 2013) and teacher' caring behavior (Lei Hao, et al., 2015), especially the teacher support on students' achievement (Perry, Liu, \& Pabian, 2010; Sit, Braman, Kerr, \& Lindner, 2013). Generally, among a number of social factors (e.g. parents, teachers, peers) to influence academic achievements, teacher support has enjoyed the most attention (Fredricks et al., 2004), consistently demonstrating a positive relationship. Teachers provided informational support (Dubow \& Ullman, 1989), which is providing someone with information or advice. Appraisal support is providing evaluative feedback to others.

Self-esteem is an individual's integrity understanding of one's capability and self-worth. In some studies self-esteem is found to be one powerful predictor of academic achievement. Meanwhile, some researches also provide evidence that there is significant correlation between teacher support and positive self-esteem and teacher support have a significant effect on academic achievement by increasing positive self-esteem. So positive self-esteem is an intermediate variable between teacher support and academic achievement. So Hypothesis 1 is put forward:

Hypothesis 1: Positive self-esteem mediates the positive relation between teacher support and migrant children's academic achievement.

Psychological control may have a moderating role which decreases the positive effect of teacher support on positive self-esteem. Therefore, in the moderation model of this study, it was predicted that the relationship between teacher support and positive self-esteem with high psychological control would be smaller compared to the one with low psychological control. So Hypothesis 2 is put forward:

Hypothesis 2: Psychological control moderates the relation between teacher support and positive self-esteem, such that the relation is weaker when the level of psychological control is high rather than low.

The prior arguments represent an integrated framework in which positive esteem mediates the positive relation between teacher support and academic achievement and psychological control moderates the relation between teacher support and positive esteem. According to the notion that psychological control moderates the relation between teacher support and positive esteem, and considering that positive esteem is positively related to academic achievement, it is logical to propose that psychological control also moderates the strength of the mediating mechanism for positive esteem in the relation between teacher support and academic achievement - a mediated moderation model (Edwards \& Lambert, 2007). As previously discussed, a weaker relation between teacher support and positive esteem will emerge among high-PC students, and the indirect effect of teacher support on academic achievement via positive esteem may also be weaker among such students. Specifically, when high psychological control reacts to academic achievement less sensitively by maintaining 
positive esteem for their performance, the indirect effect of teacher support on academic achievement should be weaker. However, when low psychological control respond to academic achievement by becoming highly worthy in their performance, the indirect effect of teacher support on academic achievement should be stronger. Hence, we propose

Hypothesis 3: Psychological control moderates the mediating effect of positive self-esteem on teacher support-migrant children's academic achievement relationship, such that the mediating effect is weaker when the level of psychological control is high rather than low.

\section{METHOD}

\section{A. Sample and Procedure}

The participants in this study were 601 pupils in Jinan, China. They were randomly recruited. The pupils were attending two migrant primary schools that served all the fourth, fifth and sixth graders in two public school districts, one of which (179) is above average achievement level near a major metropolitan area, the other (422) is of average in rural-urban fringe zone. Of the 601 participants, 307(51.1\%) were boys and 294(48.9\%) were girls; 221 (36.8\%) were fourth graders, $206(34.3 \%)$ were fifth graders and $174(28.9 \%)$ were from six graders Participants' mean age was 11.30 years $(S D=0.86)$. All the participants were born outside of Jinan city. None of them had Jinan residence card. To participate in the study, it is necessary to require parental permission. Informed consents were distributed to each migrant child's parents. The survey wasn't held until all parental informed consents were returned. Surveys lasted about 40 minutes in give instruction if anything was unclear Two research assistants in one classroom administered the survey, monitored the progress of the participants, and give instructions if the participant has anything unclear. Participants were assured that the information they provided would be absolutely confidential. Research assistants asked the participant to provide student numbers, grade for crediting purposes.

After surveys completed, participants received a token gift, of small monetary value. Of the 601 migrant children, none were excluded for incomplete data.

\section{MEASURES}

\section{A. Teacher Support}

We administered Teacher behavior Questionaire developed by Ouyang and Song (2005) to assess the extent to which students perceive their teachers' support. We assessed teacher support using a 15-item self-report scale comprising three subscales: (a) perceived teacher learning support (e.g., "when I give wrong answers, the teacher will often explain the reason why I did wrong and tell me how to correct them", 4 items) (b) perceived teacher affective support (e.g., "ask me to answer the question with encouraging eyes", 5 items)and (c) perceived teacher ability support (e.g., "believe me that I can always complete difficult task or assignment", 6 items). Qiao's study showed the inventory has a good reliability and validity among Chinese children (Qiao et al., 2013). In the present study, the teacher support demonstrated good internal consistency in our sample, with Cronbach's alpha coefficients of .71, .79 and .85, respectively. Confirmatory factor analysis (CFA) using Lisrel 8.70 of the scale has shown an excellent fit of the model: $\chi 2 / \mathrm{df}=3.48, \mathrm{RMSEA}=0.06, \mathrm{NNFI}=0.97, \mathrm{CFI}=$ $0.98, \mathrm{NFI}=0.97$.

\section{B. Self-esteem Scale (SES)}

Rosenberg Self-Esteem Scale (Rosenberg, 1965) is a 10-item Scale consisting of 5 positive items and 5 negative items, which separately assess two sides of self-assessment: positive self-esteem and negative self-esteem. The items are rated on a 4-point Likert scale from 1(not at all true) to 4(very true). CFA of the scale has shown an excellent fit of the model: $\chi 2 / \mathrm{df}=2.87$, RMSEA $=0.06, \mathrm{NNFI}=0.96, \mathrm{CFI}=0.97, \mathrm{NFI}=0.96$.

\section{Parents' Psychological Control}

Parents' psychological control was measured by 18 items selected from prior researches (Cheung et al., 2011; Wang et al., 2007; Barber, 1996; Silk et al., 2003). Using 5-point Likert Scale from 1(not at all true) to 5 (very true), Children report the extent to which they perceived parents' psychological control, which are divided by 3 subscales, (a) guilt induction (e.g., "My parents tell me that I should feel ashamed when I do not do as they wished", 10 items); (b) love with drawl (e.g., "If I hurt my parents' hearts, they don't speak to me until what I do makes them happy", 5 items); (3) authority assertion (e.g., "Parents say I will gratify them what they do for me when I grow up", 3 items). Mean scores of the 18 items are accounted, higher scores meaning parents' higher psychological control. CFA of the scale has shown an adequate fit of the model: $\chi 2 / \mathrm{df}=4.20, \mathrm{RMSEA}=0.07$, $\mathrm{NNFI}=0.92, \mathrm{CFI}=0.93, \mathrm{NFI}=0.92$.

\section{Academic Scores}

We obtained students' academic performance data of Chinese, math and English, which are proved to be the effective indicators of testing Chinese children's academic performance for the current semester from the dean office( Chen,Rubin,1997) .

\section{RESUlTS}

\section{A. Confirmatory Factor Analyses}

Because the variables of teacher support, psychological control, and positive self-esteem came from the same source, CFAs are used to test the construct validity before testing our hypotheses. Firstly we examined the baseline model that included all three variables. The overall model's chi-square, CFI, RMSEA, and TLI were applied to assess the model fit. 
TABle 1. MEANS, STANDARD DEVIATIONS, AND CORRELATIONS

\begin{tabular}{|c|c|c|c|c|c|c|c|c|c|}
\hline Variable & $M$ & $S D$ & 1 & 2 & 3 & 4 & 5 & 6 & 7 \\
\hline 1 Gender $^{a}$ & 0.51 & 0.50 & - & & & & & & \\
\hline 2 Age & 11.30 & 0.86 & . $0 \begin{array}{ll}0 & 3\end{array}$ & - & & & & & \\
\hline $3 \mathrm{TS}$ & 3.76 & 0.82 & $-.09 *$ & $-.09 *$ & $(.91)$ & & & & \\
\hline $4 \mathrm{PC}$ & 2.88 & 0.84 & $.18 * * *$ & .01 & $-.09 *$ & $(.84)$ & & & \\
\hline 5 PSE & 3.03 & 0.56 & . $0 \begin{array}{ll}0 & 3\end{array}$ & -.01 & $.44 * * *$ & . 03 & $(.73)$ & & \\
\hline $6 \mathrm{NSE}$ & 1.93 & 0.70 & . $\begin{array}{ll}0 & 1\end{array}$ & .08 & $-.24 * * *$ & $.41 * * *$ & $-.33 * * *$ & $(.76)$ & \\
\hline 7 Achievement & 0 & 2.63 & $-.16^{* * *}$ & -.07 & $.30 * * *$ & $-.18 * * *$ & $.25 * * *$ & $-.24 * * *$ & 1 \\
\hline
\end{tabular}

Note: $\mathrm{N}=601$. Values in parentheses on the diagonal are the Cronbach's alpha value of each scale.

TS = Teacher Support; PC = Psychological Control; PSE = Positive Self-esteem; NSE = Negative Self-esteem.

a Females were coded as 0 and males were coded as 1.

$* \mathrm{p}<.05$, two-tailed. $* * \mathrm{p}<.01$, two-tailed. $* * * \mathrm{p}<.001$, two-tailed.

\section{B. Descriptive Statistics}

Table 1 presents the means, standard deviations, and zero-order Pearson correlations of all key variables. As shown in Table 1, teacher support was positively correlated with positive self-esteem $(r=.44 \mathrm{p}<.001)$ and academic achievement $(\mathrm{r}=.30, \mathrm{p}<.001)$. Moreover, positive self-esteem was positively correlated with academic achievement $(\mathrm{r}=.25, \mathrm{p}<.001)$. These results provide initial support for our hypotheses.

\section{Hypothesis Testing}

A hierarchical multiple regression analysis is conducted to test Hypotheses 1 and 2. Hypothesis 1 predicts positive self-esteem mediates the positive relation between teacher support and migrant children's academic achievement. The variables are entered into the model by three steps. The control variables were entered first, followed by the independent variable of teacher support and, finally, the mediator (positive self-esteem) was entered to test the mediation effect.

TABLE 2. RESUltS OF HIERARCHICAL REGRESSION ANALYSIS

\begin{tabular}{|c|c|c|c|c|c|c|c|c|}
\hline & \multicolumn{4}{|c|}{ Positive Self-esteem } & \multicolumn{4}{|c|}{ Academic Achievement } \\
\hline & $\mathrm{M}_{1}$ & $\mathrm{M}_{2}$ & $\mathrm{M}_{3}$ & $\mathrm{M}_{4}$ & $\mathrm{M}_{5}$ & $\mathrm{M}_{6}$ & $\mathrm{M}_{7}$ & $\overline{\mathrm{M}_{8}}$ \\
\hline \multicolumn{9}{|c|}{ Control variables } \\
\hline Gender & .03 & .07 & .06 & .09 & $-.16^{* * * *}$ & $-.14^{* *}$ & $-.17 * *$ & $-.15^{* * * *}$ \\
\hline Age & -.01 & .03 & .03 & .02 & -.07 & -.05 & -.07 & -.05 \\
\hline \multicolumn{9}{|c|}{ Independent variable } \\
\hline $\mathrm{TS}$ & & $.43^{* * * *}$ & $.43 * * *$ & $.46^{* * * *}$ & & $.27 * * *$ & & $.21 * * *$ \\
\hline \multicolumn{9}{|l|}{ Moderator } \\
\hline PC & & & .06 & .06 & & & & \\
\hline \multicolumn{9}{|l|}{ Interaction } \\
\hline $\mathrm{TS} \times \mathrm{PC}$ & & & & $-.16^{* * * *}$ & & & & \\
\hline \multicolumn{9}{|l|}{ Mediator } \\
\hline PSE & & & & & & & $.22 * * *$ & $.13^{* * * *}$ \\
\hline$R^{2}$ & .00 & .18 & .19 & .21 & .03 & .10 & .08 & .12 \\
\hline$\Delta R^{2}$ & .00 & $.18^{* * * *}$ & .01 & $.02 * * *$ & $.03^{* * *}$ & $.07 * * *$ & $.05^{* * *}$ & $.02 * * *$ \\
\hline$F$ & 31 & $41.91^{* * *}$ & $32.14^{* * * *}$ & $29.96^{* * * *}$ & $9.4^{* * *}$ & $21.94^{* * * *}$ & $66.74 * * * *$ & $18.97^{* * * *}$ \\
\hline
\end{tabular}

Note: $\mathrm{N}=601$.

TS = Teacher Support PC = Psychological Control; PSE = Positive Self-esteem; NSE = Negative Self-esteem.

$* \mathrm{p}<.05$, two-tailed. $* * \mathrm{p}<.01$, two-tailed. $* * * \mathrm{p}<.001$, two-tailed.

As is shown in table 2 , teacher support was positively related to positive self-esteem $(\beta=.43, \mathrm{p}<.001$, Model 2$)$ and academic achievement $(\beta=.27, \mathrm{p}<.001$, Model 6$)$. What's more, positive self-esteem was positively related to academic achievement $(\beta=.22, \mathrm{p}<.001$, Model 7). Finally, when positive self-esteem was entered, it was positively related to academic achievement $(\beta=.13, p$ $<.001$, Model 8), Meanwhile teacher support was positively related to academic achievement $(\beta=.21, \mathrm{p}$ $<.001$, Model 8). Thus, Hypothesis 1 was supported.

Hypothesis 2 predicts that psychological control moderates the relation between teacher support and positive self-esteem, such that the relation is weaker when the level of psychological control is high rather than low, between which exists significant difference. As is shown in Table 2, the interaction teacher support and psychological control was negatively related to positive self-esteem $(\beta=-.16, \mathrm{p}<.001$, Model 4). Using Stone and Hollenbeck's (1989) procedure, we measured the interaction effects. Slope test as is shown in Figure 2 demonstrated that teacher support is less positively related to positive self-esteem when psychological control is high $(\mathrm{r}=.32, \mathrm{p}<.01)$ than low $(\mathrm{r}=.53, \mathrm{p}$ $<.001)$. Hence, Hypothesis 2 was supported.

Hypothesis 3 predicts psychological control moderates the mediating effect of positive self-esteem on 
teacher support-migrant children's academic achievement relationship. To test this hypothesis, we employed Edwards and Lambert's (2007) general path analytic framework was employed. The results, measured in Table 3, show that the size of the difference in the indirect effect of teacher support on academic achievement was .09, with the $99 \%$ confidence intervals computed using bootstrap estimates excluding zero. Specifically, the indirect effect of positive self-esteem on the relation between teacher support and academic achievement was significantly stronger at a low level of psychological control. Thus, Hypothesis 3 was supported.

Figure 1. The Moderating Effect of Psychological Control on the Relationship between Teacher Support and Positive Self-esteem

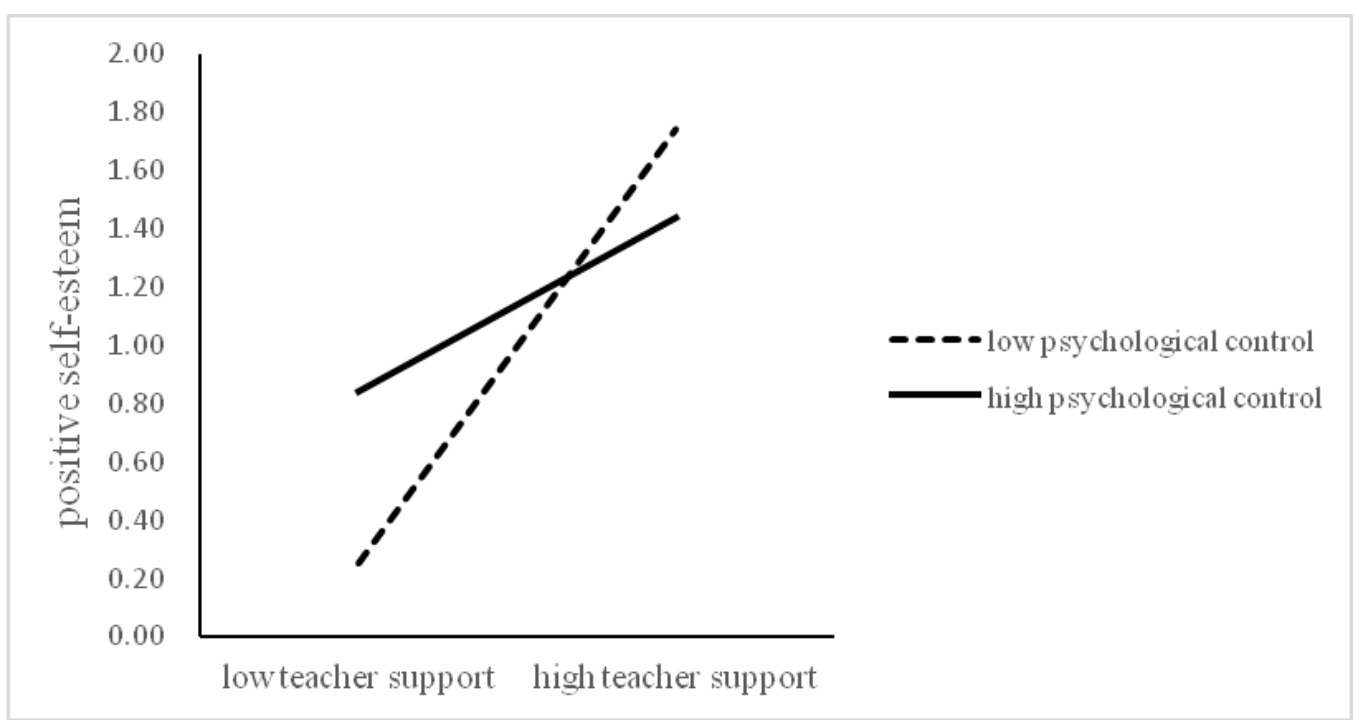

TABLE 3. RESULTS OF MODERATED PATH ANALYSIS

\begin{tabular}{|c|c|c|c|c|c|}
\hline \multirow[b]{4}{*}{ Moderator Variable } & \multicolumn{5}{|c|}{ Teacher Support $(\mathrm{X}) \rightarrow$ Positive Esteem $(\mathrm{M}) \rightarrow$ Academic Achievement $(\mathrm{Y})$} \\
\hline & \multicolumn{2}{|c|}{ Stage } & \multicolumn{3}{|c|}{ Effect } \\
\hline & First & Second & $\begin{array}{l}\text { Direct } \\
\text { Effects }\end{array}$ & $\begin{array}{l}\text { Indirect } \\
\text { Effects }\end{array}$ & $\begin{array}{c}\text { Total } \\
\text { Effects }\end{array}$ \\
\hline & $\mathrm{P}_{\mathrm{MX}}$ & $\mathrm{P}_{\mathrm{YM}}$ & $\mathrm{P}_{\mathrm{YX}}$ & $\begin{array}{l}\left(\mathrm{P}_{\mathrm{MX}} *\right. \\
\left.\mathrm{P}_{\mathrm{YM}}\right)\end{array}$ & $\begin{array}{c}\left(\mathrm{P}_{\mathrm{YX}}+\mathrm{P}_{\mathrm{MX}} *\right. \\
\left.\mathrm{P}_{\mathrm{YM}}\right)\end{array}$ \\
\hline $\begin{array}{l}\text { Simple paths for } \\
\text { Low psychological } \\
\text { control }\end{array}$ & $.53^{* * * *}$ & $.32^{* * *}$ & $.24 *$ & .17 & .41 \\
\hline $\begin{array}{l}\text { Simple paths for } \\
\text { high psychological } \\
\text { control }\end{array}$ & $.32^{* *}$ & $.25^{*}$ & $.23^{*}$ & .08 & $.31 * *$ \\
\hline Differencs & $.21 * *$ & .07 & .01 & $.09 *$ & $.10^{*}$ \\
\hline
\end{tabular}

Note: ${ }_{\mathrm{N}}=235 . \mathrm{P}_{\mathrm{MX}}=$ path from teacher support to positive self-esteem; $\mathrm{P}_{\mathrm{YM}}=$ path from positive self-esteem to academic achievement; $\mathrm{P}_{\mathrm{YX}}=$ path from teacher support to academic achievement. Low psychological control refers to one standard deviation below the mean of psychological control; high psychological control refers to one standard deviation above the mean of psychological control. Tests of differences for the indirect and total effects are based on bias-corrected confidence intervals derived from bootstrap estimates.

$* * \mathrm{p}<.01$, two-tailed. ***p $<.001$, two-tailed.

Moreover, the results presented in Table 3 support a first-stage moderating effect $(\Delta \beta=.21, \mathrm{p}<.01)$, suggesting that teacher support interacts with

\section{DISCUSSION}

This study examined the mediator effects of positive self-esteem and moderator effects of psychological control for the relationship between teacher support and academia achievement in migrant children. As expected, the previous findings of the study indicate that teacher support has a relationship with positive self-esteem and academic achievement at a high level of significance. psychological control to predict positive self-esteem, which, in turn, influences academic achievement. Thus, Hypothesis 2 was further supported.

These results are consistent with earlier studies reporting a relationship between teacher support and positive self-esteem and academic achievement. Moreover, even when gender, age, and teacher support were controlled, it was observed that positive self-esteem can be a significant predictor of academic achievement. This finding supports earlier research that shows that self-esteem is one of the strongest variable predictors of academic achievement. 
In this study, as expected, positive self-esteem played a mediator function partially between teacher support and academic achievement. In other words, migrant children with high levels of teacher support are likely to engage in high positive self-esteem, which in turn contributed to enhanced academic achievement. These results are consistent study that reported that positive self-esteem mediated the relationship between teacher support and academic achievement in migrant children. Positive Self-esteem as a positive evaluation will enhance an individuals' hard work, thus it can be expected that they will have better academic achievement. In this way, it can be shown that teacher support reflects more positively on academic achievement with the help of positive self-esteem.

Another interesting result of this study is that psychological moderated the influence of teacher support on positive self-esteem and the mediating effect of positive self-esteem on teacher support-migrant children's academic achievement relationship. When migrant children reported a high level of positive self-esteem, those with high teacher support reported higher academic achievement than those with low teacher support.

\section{ACKNOWLEDGEMENT}

This research was supported by Shandong Social Science Planning Research Project (15CJYJ04). We are grateful to all the children and teachers who participated or contributed to this project.

\section{REFERENCES}

[1] Population Census Office under the State Council (2012). Tabulation on the 2010 population census of the People's Republic of China. Beijing, China: China Statistics Press.

[2]Perry, J. C., Liu, X., \& Pabian, Y. (2010).School engagement as a mediator of academic performance among urban youth: The role of career support, parental career support and teacher support. The Counseling Psychologist, 38, 269-295.

[3]Edwards, J. R., Lambert, L. S. (2007) .Methods for integrating moderation and mediation: a general analytical framework using moderated path analysis. Psychological Methods, 12, 1-22.

[4]Lei.H., Xu G., Shang C.-S. J.(2015). The Relationship of Teachers' Caring Behavior and Students' Academic Development: The Mediating Role of Learning Self-efficacy. Psychological Development and Education, 38, 188-197.

[5] Fan, X. H., Fang, X. Y., Liu, Y., Lin, X. Y., \& Yuan, X. J. (2012) The effect of social support and social identity on the relationship between perceived discrimination and socio-cultural adjustment among Chinese migrant children. Act a Psychologica Sinica, 44, 647-663.

[6] Jia, X., \& Liu, X. (2016). Perceived discrimination and antisocial behaviour among Chinese rural-to-urban migrant adolescents: Mediating effects of social support. International Journal of Psychology, 1-9.

[7] Anna D. Strati , Jennifer A. Schmidt and Kimberly S. Maier Perceived Challenge, Teacher Support, and Teacher Obstruction as Predictors of Student Engagement. Journal of Educational Psychology, 1-17.

[8] Zhang, H., Kwan, H. K., Zhang, X., \& Wu, L. Z. (2014). High core self-evaluators maintain creativity: a motivational model of abusive supervision. Journal of Management, 40, 1151-1174.

[9] Pekrun, R., \& Linnenbrink-Garcia, L. (2012). Academic emotions and student engagement. In S. L. Christenson, A. L. Reschly, \& C. Wylie (Eds.), Handbook of research on student engagement (pp. 259-282). New York, NY: Springer.

[11] Barber, B. K., Stolz, H. E., \& Olsen, J. A. (2006). Parental support, psychological control, and behavioral control: Assessing relevance across time, culture, and method. Monographs of the Society for Research in Child Development, 70, 1 - 147.

[12] Barber, B. K. (2002). Intrusive parenting: How psychological control affects children and adolescents. Washington, DC: American Psychological Association.

[13] Passanisi, A., Gensabella, A., \& Pirrone, C. (2015). Parental bonding, self-esteem and theory of mind among locals and immigrants. Procedia - Social and Behavioral Sciences, 1702-1706. 